Ann. Zootech., I979, 28 (4), 453-458.

Note

\title{
Influence du taux protéique de la ration sur la composition corporelle du lapin
}

\author{
J. OUHAyOUN, Danièle DEImAas et F. IEBAS \\ Laboratoire de Recherches sur l'Élevage du Lapin \\ Centre de Recherches de Toulouse, I.N.R.A., \\ 31320 Castanet-Tolosan (France)
}

\section{Résumé}

Deux régimes isoénergétiques et à teneurs en protéines équilibrées différentes : 13 et I 6 p. Ioo, distribués ad libitum, sont comparés sur la croissance de lapins de race californienne, entre l'âge de 35 jours et le poids individuel de $2,2 \mathrm{~kg}$. Les lapins soumis au régime à faible teneur en protéines ont une vitesse de croissance fortement réduite : un retard moyen de 6 jours dans l'atteinte du poids de $2,2 \mathrm{~kg}$ est observé. Jusqu'à 63 jours, leur indice de consommation est sensiblement détérioré; ils utilisent, ensuite, ce régime avec plus d'efficacité, puisque, entre l'âge de 35 jours et le poids de $2,2 \mathrm{~kg}$, leur indice de consommation est égal à celui des lapereaux nourris avec le régime à $\mathrm{I} 6 \mathrm{p}$. Ioo de protéines (tab1. I). Il en résulte que les protéines végétales incorporées dans l'aliment à raison de $\mathrm{I} 3 \mathrm{p}$. I oo sont mieux valorisées. Les principales caractéristiques bouchères des lapins : poids, adiposité, rapport muscle /os de la carcasse, composition chimique du tissu musculaire (tabl. 2), ne sont pas sensiblement affectées par les variations de la vitesse de croissance induites expérimentalement.

\section{Introduction}

L'efficacité productive du Lapin de chair peut être améliorée par augmentation de la vitesse de croissance du jeune animal, car cette dernière est accompagnée d'une réduction de l'indice de consommation (PRUD'HON, I967). Pour produire des carcasses de I,4 kg, poids commercial optimal, plusieurs voies peuvent être empruntées. L'une d'entre elles consiste à utiliser des souches de grande taille adulte, à forte vitesse de croissance dans le jeune âge, abattues précocement; mais les lapereaux n'atteignent alors pas 50 p. Ioo de leurs poids adulte et, par conséquent, les carcasses ont un état d'engraissement insuffisant (OuHAyoun, 
I978). A l'opposé, l'utilisation de souches de format moyen et à croissance rapide fournit des carcasses présentant une adiposité importante (PRUD'HON, VEZINHE'T et CANTIE, I970), voire excessive. La demande actuelle d'une production cunicole de qualité, la nécessaire réduction des cônts de production, justifient la maîtrise du développement relatif des tissus de la carcasse. Celui-ci dépend du rythme et des limites de la croissance des lapereaux.

Le but de la présente étude est d'apprécier l'incidence, sur la composition corporelle, de la modification par voie nutritionnelle de la vitesse de croissance postsevrage d'une souche de format adulte moyen. A cet effet, denx régimes caractérisés par la même concentration en énergie digestible mais différant par le taux protéique sont utilisés. Les protéines apportées par du tourteau de soja sont équilibrées en acides aminés soufrés par addition de $d l$ méthionine.

\section{Matériel et méthodes}

L'étude porte sur des lapereaux des deux sexes de la souche californienne du laboratoire. Le sevrage est réalisé de façon progressive : à 1'âge de 4 semaines, les lapereaux séparés de leur mère sont maintenus en collectivité et soumis à un régime mixte, constitué, pour moitié, de l'aliment maternel, et, pour un quart, de chacun des deux régimes expérimentaux. Le régime expérimental de base, titrant $16 \mathrm{p}$. Ioo de protéines, est composé de tourteau de soja à 50 p. Ioo de protéines (32 p. I0o), d'amidon de mais ( $36,8 \mathrm{p}$. I00), de cellulose colmacel (4 p. IOO), de paille de blé (20 p. Ioo), d'huile de maïs ( 3 p. IOo); il est additionné de $d l$ méthionine (0,2 p. I0o) et d'un complément minéral vitaminé (4 p. Ioo). Le second régime, titrant I3 p. Ioo de protéines, contient moins de farine de soja (24 p. Ioo) et, en contrepartie, plus d'amidon $(42,9 \mathrm{p}$. IOo) et de cellulose (6 p. Ioo), et moins de $d l$ méthionine (o, I p. IOo). A 5 semaines, douze couples de lapereaux de même poids vif sont constitués. Les 24 lapins échantillonnés sont placés en cages individuelles; ils reçoivent, à volonté, l'un des deux régimes expérimentaux. Les animaux sont abattus lorsqu'ils atteignent le poids de $2200 \pm 3^{\circ} \mathrm{g}$. Les contrôles portent sur la croissance pondérale, la consommation d'aliment, les caractéristiques bouchères des carcasses : rendement à l'abattage, adiposité estimée par pesée des dépôts adipeux périrénaux, rapport muscle/os d'un membre postérieur, et sur la composition chimique de l'homogénat des muscles provenant de la dissection de ce groupe anatomique : eau, lipides, protéines. Les caractères de croissance et de consommation sont analysés entre 35 et 63 jours, période de vie commune à tous les lapereaux. Au-delà, les effectifs décroissent par suite des abattages au poids individuel de $2,2 \mathrm{~kg}$. Une seconde période, de durée variable selon les individus est done analysée; elle est comprise entre la mise en lots ( 35 jours) et l'abattage $(2,2 \mathrm{~kg})$.

\section{Résultats et discussion}

Entre 35 et 63 jours, les lapereaux soumis au régime à I 3 p. Ioo de protéines ont la plus faible vitesse de croissance. Il est vrai que cela est associé à une diminution des quantités d'aliment et, par conséquent, des quantités d'énergie ingérées. I,eur indice de consommation est sensiblement dégradé, mais de façon non signi- 


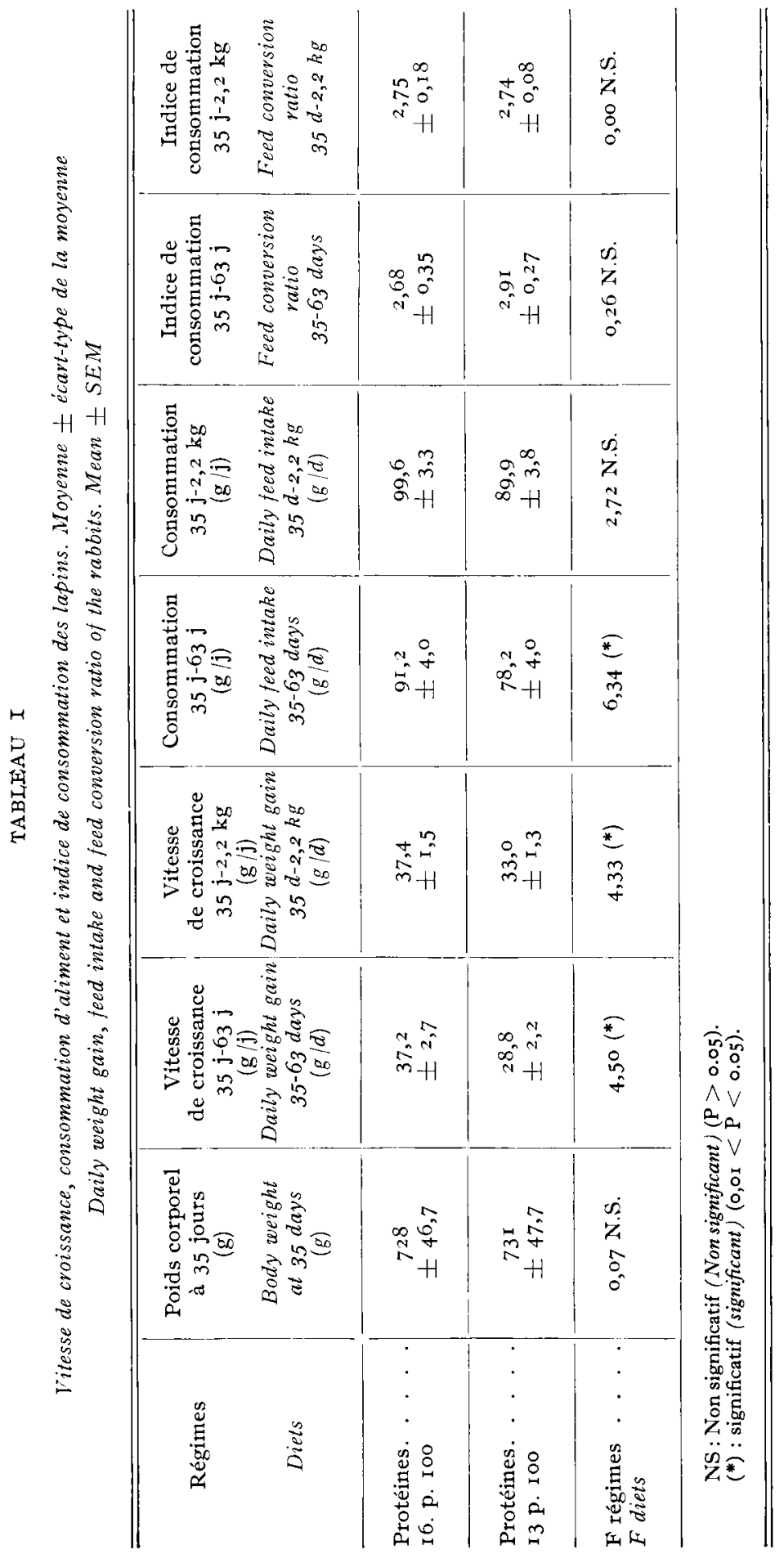




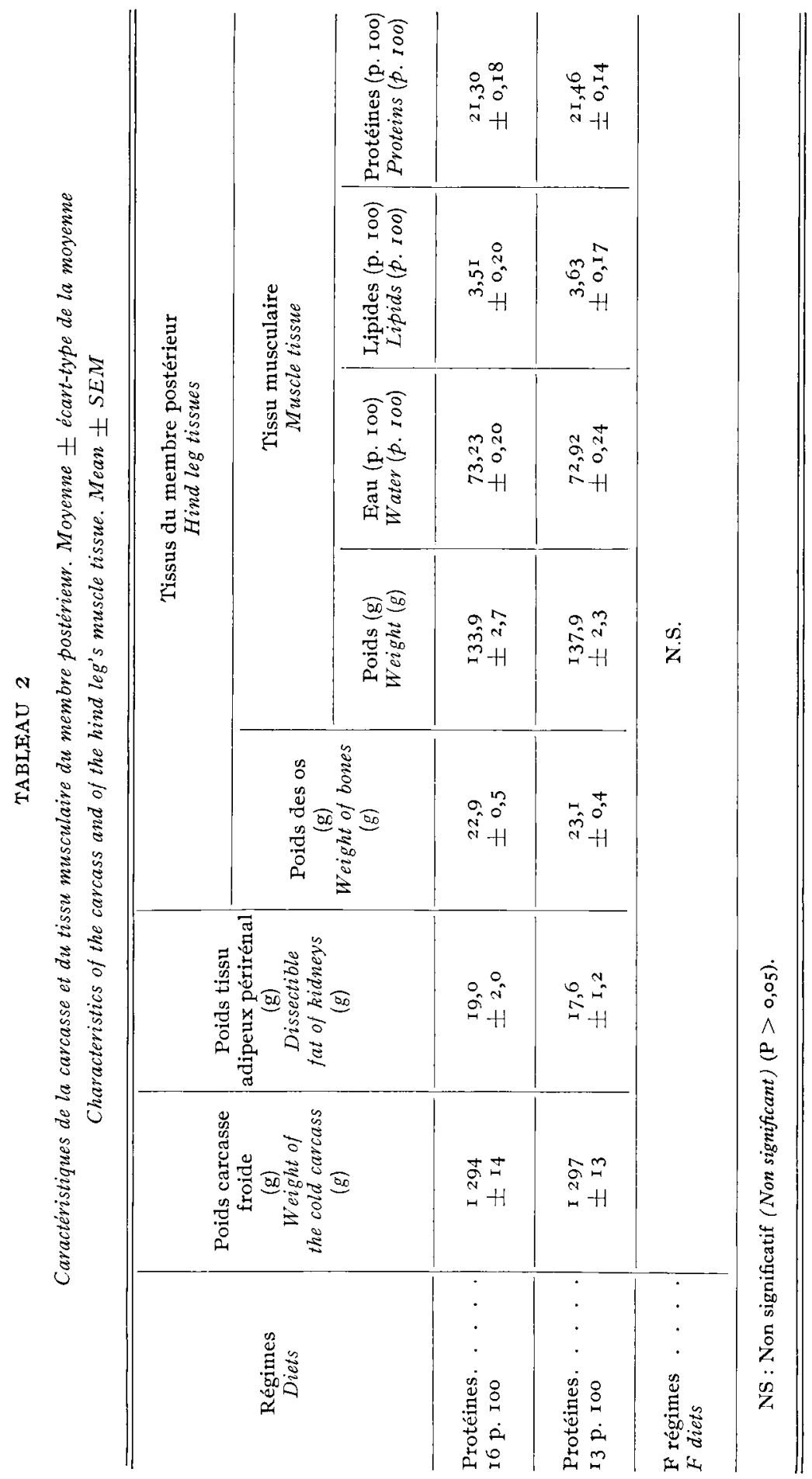


ficative (tableau I). L'influence propre du taux azoté de l'aliment sur la vitesse de croissance pondérale mériterait d'être isolée par comparaison de lots de lapereaux recevant des quantités égales d'énergie.

Globalement, entre l'âge de 35 jours et le poids corporel de $2,2 \mathrm{~kg}$, la vitesse de croissance et la consommation d'aliment sont inférieurs, de près de II p. Ioo avec le régime le plus pauvre en protéines. Il résulte, des différences de vitesse de croissance observées, un accroissement significatif du délai moyen ( 6 jours environ) mis par les animaux, consommant cet aliment, pour atteindre le poids imposé de $2,2 \mathrm{~kg}$. Les indices de consommation des deux aliments sont égaux; l'efficacité de la transformation des protéines végétales en poids corporel est donc supérieure avec l'aliment le plus pauvre en protéines. Ces résultats montrent que les lapereaux souffrent d'une insuffisance protéique de l'aliment pendant la période initiale de leur croissance postsevrage mais qu'ils sont ultérieurement capables d'extérioriser pleinement leur potentiel de rétention azotée. PrUd'Hon, CoLIN et LEBAS (I977) ont déià montré une telle réduction avec l'âge de la sensibilité du lapin à une insuffisance ou à un déséquilibre protéique alimentaire.

Malgré les différences de rythme de croissance créées expérimentalement, les caractéristiques moyennes des carcasses et du tissu musculaire des deux groupes de lapins ne présentent pas de différences significatives (tabl. 2). Mais des tendances méritent d'être examinées. En effet, les carcasses des animaux soumis au régime riche en protéines, dont la croissance est relativement rapide (poids individuel de $2,2 \mathrm{~kg}$ atteint à 75 jours, en moyenne), tendent à avoir plus de tissu adipeux périrénal que celles de même poids obtenues plus lentement avec le régime à I3 p. Ioo de protéines ( $8 \mathrm{I}$ jours, en moyenne). Par contre, le membre postérieur est plus léger, ce qui est attribuable surtout à une réduction des masses musculaires. Le rapport muscle/os est inférieur. Les écarts observés n'ont pas l'ampleur de ceux mis en évidence par PRUD'hon, Vezinhet et CANTIER (I970) entre des sujets ayant atteint le poids de carcasse de I $500 \mathrm{~g}$ en 74 ou en 106 jours, mais ils sont de même sens. La musculature du membre postérieur des lapereaux alimentés avec le régime à haut niveau en protéines, qui est pondéralement la moins développée, est plus riche en eau et plus pauvre en protéines et en lipides.

Prud'hon, Vezinhet et Cantier (1970) ont montré qu'il existe, chez le lapin commun, un gradient le précocité dans le développement des différents dépôts adipeux; ceux-ci apparaissent successivement aux niveaux superficiel, périviscéral, intermusculaire et enfin périrénal. Or, dans la présente étude, les sujets dont les carcasses comportent les plus importants dépôts périrénaux ne sont pas ceux qui présentent les plus fortes infiltrations lipidiques musculaires. Au contraire, ces dernières sont, en effet, remarquées chez les lapereaux dont la musculature est la plus développée, c'est-à-dire, chez ceux qui, soumis au régime à bas niveau protéique, ont la croissance pondérale la plus lente. Cet aspect mérite d'être étudié de façon plus approfondie, car il est important de savoir si la composition du régime, outre son effet sur la proportion des trois principaux tissus constitutifs de la carcasse, a une influence sur la répartition anatomique des dépôts adipeux.

En conclusion, bien qu'une réduction du taux protéique de la ration entraîne un ralentissement sensible de la croissance pondérale postsevrage, les caractéristiques bouchères des lapereaux abattus à poids constant sont peu modifiées. Dans ces conditions, il est permis de s'interroger sur l'utilité de porter à $16 \mathrm{p}$. Ioo le taux en protéines de 1'aliment. Ces résultats devront être confirmés. En particulier, les effets sur la vitesse de croissance du taux protéique et du niveau de l'ingestion énergétique méritent d'être distingués. 


\section{Summary}

\section{Body composition of rabbits as affected by the dietary protein level}

Two isoenergetic diets containing either I 3 or 16 p. I oo balanced proteins were offered ad libitum to Californian rabbits in order to compare their growth between the age of 35 days and an individual weight of $2.2 \mathrm{~kg}$. The growth rate of the rabbits fed the low protein diet was greatly reduced (a delay of 6 days before they reached the weight of $2.2 \mathrm{~kg}$ ). Until the age of 63 days, the feed conversion ratio of these rabbits was substantially deteriorated. However, after that period the diet was used more efficiently since the feed conversion ratio was similar to that of the rabbits fed the I $6 \mathrm{p}$. I oo protein diet when taking as a basis the whole experimental period, i.e. from the age of 35 days and until slaughter $(2.2 \mathrm{~kg}$ ) (Table $\mathrm{I}$ ). Accordingly, the plant proteins included in the low protein diet ( 3 p. Ioo) were better valorized. The main carcass traits (carcass weight, fatness, muscle/bone ratio, chemical composition of the muscle tissue) (Table 2) were not much affected by the experimentally induced variations in the growth rate of the rabbits.

\section{Références bibliographiques}

Cantier J., Vezinher A., RouvifR R., Dauzifir L., i 969 . Allométrie de croissance chez le Lapin (Oryctolagus cuniculus). I. - Principaux organes et tissus. Ann. Biol. anim. Bioch. Biophys., 9, 5-39.

Oumayoun J., r978. F́tude comparative de races de lapins différant par le poids adulte. Thèse de $3^{\mathrm{e}}$ cycle, Montpellier, $104 \mathrm{pp}$.

Prud'hon M., i967. L'appétit du Lapin alimenté à sec. Bull. Tech. Inf., 219, I-i6.

Prud'hon M., Vezinhet A., CANTIER J., I97o. Croissance, qualités bouchères et coût de production des lapins de chair. Bull. Tech. Int., 248, I-ro.

Prud'hon M., Colin M., LEBas F., I977. Effet de l'addition de méthionine au régine sur les caractéristiques du comportement alimentaire du Lapin en croissance. Ann. Zootech., 26, $42 \mathrm{r}-428$. 